\title{
Treatment with a probiotic combination reduces abdominal adhesion in rats by decreasing intestinal inflammation and restoring microbial composition
}

\author{
XIAORONG DENG $^{1 *}$, CIHUA ZHENG $^{1 *}$, SHUAI WANG $^{1}$, RONG YANG $^{1}$, ZHAOXIA LIU $^{2}$ and TINGTAO CHEN ${ }^{1,3}$ \\ Departments of ${ }^{1}$ Gastrointestinal Surgery, and ${ }^{2}$ Obstetrics and Gynecology, \\ The Second Affiliated Hospital of Nanchang University, Nanchang, Jiangxi 330006; \\ ${ }^{3}$ National Engineering Research Center for Bioengineering Drugs and Technologies, \\ Institute of Translational Medicine, Nanchang University, Nanchang, Jiangxi 330031, P.R. China
}

Received August 14, 2019; Accepted December 11, 2019

DOI: $10.3892 /$ or.2020.7463

\begin{abstract}
Abdominal adhesions refer to abnormal adhesions which cause a series of complications in numerous patients. In the present study, the beneficial effect of a combination of probiotics (Lactobacillus plantarum, L. acidophilus, L. rhamnosus and Bifidobacterium animalis) on abdominal adhesions in a rat model were verified. The present results indicated that probiotic treatment significantly reduced the levels of proinflammatory factors interleukin (IL)-1 $\beta$, IL-6 and TNF- $\alpha$ in serum and intestinal tissue $(\mathrm{P}<0.05)$, and markedly downregulated the inflammatory (TLR4/NF- $\kappa \mathrm{B})$ and fibrotic (TGF- $\beta 1 / \mathrm{Smad}$ ) signalling pathways in intestinal tissue, especially in the prevention group $(\mathrm{P}<0.01)$. The high-throughput sequencing results further supported that the probiotics significantly increased the relative abundance of probiotic Bacteroidetes (at the phylum level), Bacteroidales (at the order level), Lactobacillales (at the order level) and Lactobacillus (at the genus level), and markedly reduced the number of pathogenic Proteobacteria (at the phylum level), Erysipelotrichales (at the order level), Verrucomicrobiales (at the order level), Klebsiella (at the genus level) and Serratia (at the genus level). In conclusion, probiotics can effectively reduce abdominal
\end{abstract}

Correspondence to: Dr Tingtao Chen, National Engineering Research Center for Bioengineering Drugs and Technologies, Institute of Translational Medicine, Nanchang University, 1299 Xuefu Road, Nanchang, Jiangxi 330031, P.R. China

E-mail: chentingtao1984@163.com

Dr Zhaoxia Liu, Department of Obstetrics and Gynecology, The Second Affiliated Hospital of Nanchang University, 1 Minde Road, Nanchang, Jiangxi 330006, P.R. China

E-mail: lzxia77@163.com

${ }^{*}$ Contributed equally

Key words: abdominal adhesion, probiotics, high-throughput sequencing, TGF- $\beta 1 /$ Smad signalling pathway, fibrosis adhesions by restoring the microbial balance and reducing inflammation and fibrosis caused by surgery.

\section{Introduction}

Abdominal adhesion refers to an abnormal adhesion between intestinal tubes, between the intestines and viscera, or between the intestines and peritoneum in the abdominal cavity (1). Abdominal adhesions can be caused by congenital or acquired factors, with acquired factors accounting for $80 \%$ of abdominal adhesion cases, including mechanical damage, peritoneal dryness, and introduction of foreign bodies (e.g., microorganisms), suture lines and the talcum powder present in surgical gloves (2), which will cause long-term abdominal pain in patients (3).

The mechanisms underlying the formation of postoperative abdominal adhesions remain unclear. Most experts support the theory of injury and inflammation, and claim that disorders of inflammatory cells, the secretion of inflammatory factors, as well as fibrin formation and dissolution at the site of injury are responsible for the formation of postoperative abdominal adhesions (this process is usually completed within 7 days of injury) (3). To prevent adhesions, surgical or adjuvant treatments are usually applied in the clinical setting (4). However, surgery cannot completely eliminate the risk of adhesions, and almost a quarter of abdominal re-exploration procedures accidentally cause intestinal injury, which may lead to the formation of a new adhesion after surgery (5). The adjuvants include drugs (anticoagulant, antibiotic and fibrinolytic drugs, as well as Chinese medicine preparations) as well as other materials (membrane materials, adhesive glue and intraperitoneal crystal solutions $(6,7)$. With regard to drugs, their effects on preventing abdominal adhesions are still unclear, and some of them may even increase the occurrence of adverse reactions, specifically bleeding of the wound after surgery and delayed wound healing (8). Regarding materials, membrane materials are difficult to apply during laparoscopic surgery or to tissues with complex geometric structures, and they become fragile and difficult to position when attached to moist surgical equipment or tissues (9). The 
crystal solution can easily become dislodged by photographic processing during surgery, and the strong absorption capacity of the abdominal cavity makes it a challenge to achieve a good curative effect (10).

Intestinal microbiota are a microecology system that is dominated by bacteria. There are approximately 1,000 different types of bacteria in the human intestine, and maintaining a balance is important for health $(11,12)$. Under physiological conditions, symbiotic physiological anaerobic bacteria coexist with symbiotic conditional pathogenic bacteria and other harmful bacteria in the intestinal tract, and their cooperation with the nonspecific immune system can protect intestinal epithelial cells from inflammation and fibrosis (13). A study revealed that intestinal inflammation was closely related to

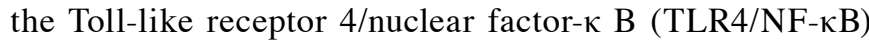
signalling pathway, in which TLR4 mainly recognizes lipopolysaccharide (LPS) of gram-negative bacteria. When TLR4 is combined with LPS, it activates the NF- $\kappa B$ pathway, causing the release of numerous pro-inflammatory factors [interleukin-1 $\beta$, (IL-1 $\beta)$; tumour necrosis factor- $\alpha$ (TNF- $\alpha$ )] to mediate the intestinal inflammation process (14). In addition, researchers contend that transforming growth factor- $\beta 1$ (TGF- $\beta 1$ ) is the initiator of fibrosis, which can transmit signals to Smad through specific receptors on the cell membrane $(15,16)$, and is closely related to multiple organ fibrosis (17).

The intestinal microbiota are known to be associated with obesity, cardiovascular disease, malnutrition, osteoporosis, Clostridium difficile infection, type 2 diabetes, colorectal cancer and inflammatory bowel disease $(18,19)$. Fedorak et al $(20)$ reported that probiotics could effectively reduce the levels of inflammatory cytokines in the mucosa and helped to prevent the recurrence of Crohn's disease after surgery. In addition, a study by Liu et al (21) revealed that probiotics had sound anti-inflammatory effects in animal models of LPS-induced colitis by inhibiting the activation of inflammatory signalling pathways $[\mathrm{NF}-\kappa \mathrm{B}$ and mitogen-activated protein kinase (MAPK)] and reducing colon fibrosis (TGF- $\beta 1$ ). To date, little research has been conducted to explore the relationship between the microbiota and abdominal adhesions, especially the potential of probiotic treatment to prevent abdominal adhesions. In China, no probiotic drug has been approved in recent decades, and the probiotic drugs currently used are older drugs with certain problems, e.g. they contain Enterococcus faecalis (found in $>75 \%$ of Chinese probiotic drugs; this strain is readily drug resistant and can spread resistant genes) $(22,23)$ and Bacillus cereus (some strains cause infection) (24,25). The Lactobacillus and Bifidobacteriium species have been revealed to have anti-inflammatory/immunomodulatory effects in experimental animal as well as human studies $(26,27)$. The beneficial effects of Lactobacillus plantarum, L. acidophilus, L. rhamnosus or Bifidobacterium animalis have been widely reported in these studies. Moreover, these probiotic strains were regarded as safe and edible by the Ministry of Health, China.

Therefore, to obtain a robust probiotic effect, a combination of these four aforementioned probiotic strains were used to investigate whether administration of a probiotic combination could help to prevent abdominal adhesions in a rat model, and to elucidate the underlying mechanism.

\section{Materials and methods}

Cultivation of probiotic bacteria. Four strains of L. plantarum MH-301 (isolated from human faeces, and stored as a patented bacterium at the Institute of Microbiology, Chinese Academy of Sciences), L. acidophilus (isolated from fermented milk), L. rhamnosus L12 and B. animalis subsp. lactis LPL-RH (both provided by Harbin Meihua Biotechnology Co., Ltd.) were used in the present study. These strains were cultured in De Man, Rogosa and Sharpe (MRS; HB0384-1; Qingdao Hope Bio-Technology, Co., Ltd.) broth for $24 \mathrm{~h}$ in an incubator at $37^{\circ} \mathrm{C}$ under anaerobic or aerobic conditions. All strains were twice activated in MRS broth, and the bacterial density of each strain was approximately $10^{9} \mathrm{CFU} / \mathrm{ml}$ via spectrophotometry.

Animal model and treatments. Forty-five male Sprague Dawley rats (8 weeks, 200-220 g) were provided by Hunan Si Lake King of Experimental Animal Co., Ltd.. Rats were housed in specific pathogen-free cages in a room with a controlled temperature $\left(22 \pm 2^{\circ} \mathrm{C}\right)$ and humidity (55-60\%), under a $12 \mathrm{~h}$ light/dark cycle, and were allowed free access to food and water. Rats were acclimated for 7 days before the study.

The animals were randomised into four groups: The control group $(C, n=9)$, treated with gelatine physiological saline (day 7 to end); the model group $(M, n=12)$, treated with gelatine physiological saline (day 7 to end) and surgery (day 10); the treatment group $(\mathrm{T}, \mathrm{n}=12)$, treated with gelatine physiological saline containing probiotic combinations with L. plantarum $\left(10^{9} \mathrm{CFU} / \mathrm{ml}\right)$, L acidophilus $\left(10^{9} \mathrm{CFU} / \mathrm{ml}\right)$, L. rhamnosus $\left(10^{9} \mathrm{CFU} / \mathrm{ml}\right)$ and $B$. animalis $\left(10^{9} \mathrm{CFU} / \mathrm{ml}\right)$ (day 17 to end) and surgery (day 10) (the dose of probiotics were determined based on our preliminary test) (28), with the rest of the treatment time (day 7 to 16) maintained the same as group $M$; and the prevention treatment group (PT, $n=12)$, pretreated with the probiotic combinations (day 7 to end) and surgery (day 10). The gelatine physiological saline contained $0.01 \%$ gelatine to coat the probiotics and prevent digestion in the stomach (Fig. 1A). The weight of the rats was measured every week before the surgery and once every 3 days during the first week after the surgery. Detailed records regarding the activities of the rats, the healing of the surgical incision and their survival condition, among others, were performed at the same intervals, and once per week thereafter.

Animal experiments were performed in a sterile environment using the clamp trauma method. The rats were fasted for $12 \mathrm{~h}$ preoperatively. Animals were anaesthetised by intraperitoneal injection with sodium pentobarbital $(40 \mathrm{mg} / \mathrm{kg}$; cat. no. B1202-005; Fluka). Once anaesthesia was achieved, the abdomen was shaved and disinfected with povidone iodine (cat. no. MDS093904; Medline Industries) and a sterile surgical towel was laid. Abdominal laparotomy was performed by an incision of $\sim 2 \mathrm{~cm}$ in diameter into the right side of the abdominal cavity. The ileocecal part was gently removed from the incision, starting $5 \mathrm{~cm}$ away from the ileocecal part. The intestinal tract on the opposite side of the mesentery was clamped with toothed tweezers and toothless tweezers at $1 \mathrm{~cm}$ intervals until subserosal haemorrhage and punctate bleeding appeared, totalling 10 places. The abdominal incision was sutured with a 3-0 nylon thread. After surgery, all rats were transferred to separate cages according to groups 

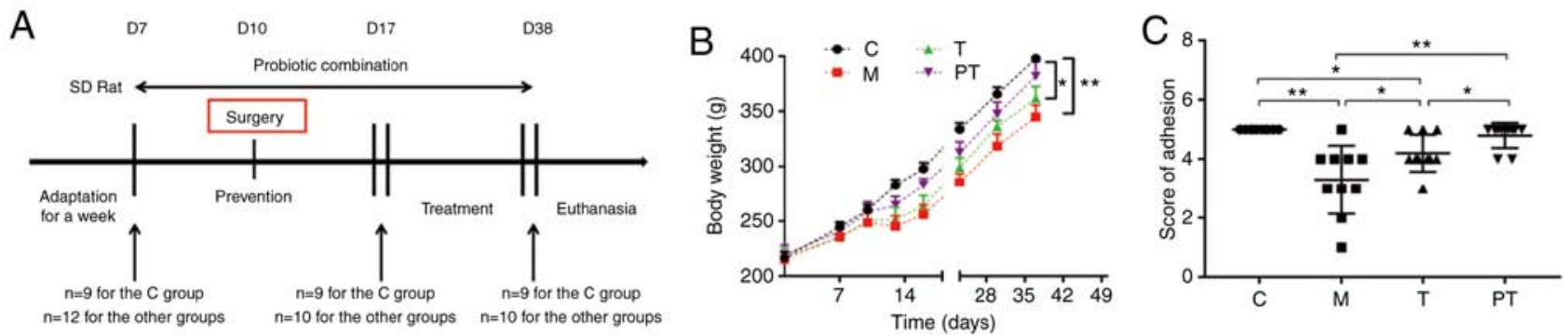

D

C

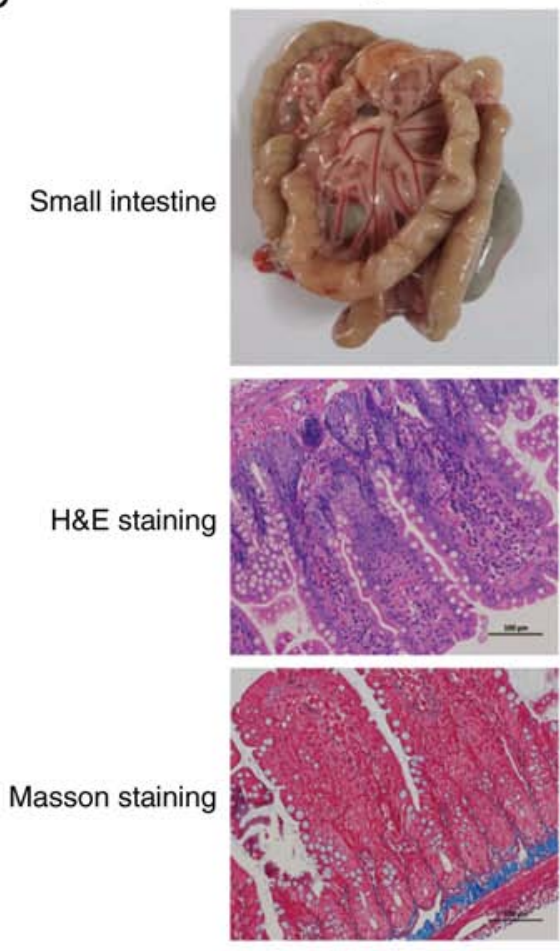

M

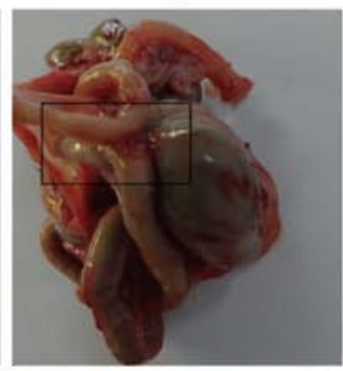

$\mathrm{T}$

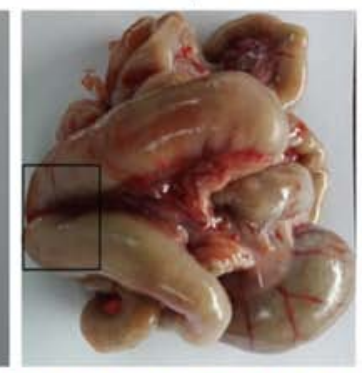

PT
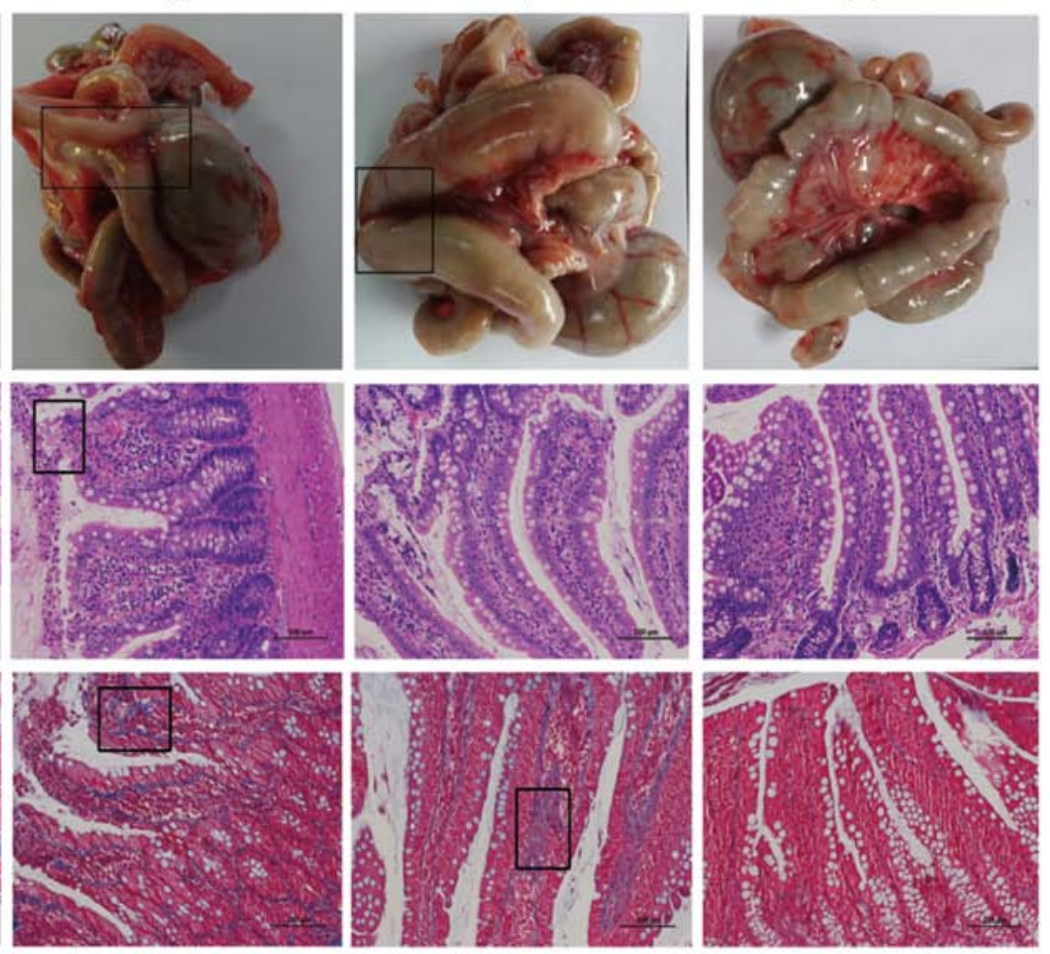

Figure 1. Effect of the probiotic combinations on the prevention or treatment of abdominal adhesion. (A) Experimental scheme to evaluate the effects of probiotic combinations on the prevention and treatment of abdominal adhesions in rat models. Effect of the probiotic combinations on (B) body weight ( $\mathrm{g}$ ) and (C) abdominal adhesion score ( $\mathrm{n}=9-12)$. (D) H\&E staining was used to observe intestinal inflammation and Masson staining was used to observe collagen deposition in rat intestinal tissue (x200, magnification, $\mathrm{n}=4$ ). C, control group; $\mathrm{M}$, model group; T, treatment group (fed $10^{9} \mathrm{CFU}$ of probiotic combinations 7 days after remodelling); PT, prevention and treatment group (fed $10^{9} \mathrm{CFU}$ probiotic combinations 3 days before remodelling). Data are presented as the means \pm SD. ns, $\mathrm{P}>0.05 ;{ }^{*} \mathrm{P}<0.05 ;{ }^{* *} \mathrm{P}<0.01$. Scale bars, $100 \mu \mathrm{m}$. H\&E, hematoxylin and eosin.

for monitoring, and their body weight, activity and survival condition were observed (10).

The present study was approved by the Ethics Committee of the Second Affiliated Hospital of Nanchang University, and all experiments were conducted in accordance with the approved guidelines.

Sample collection and evaluation of adhesion. On day 28 after surgery, all rats were euthanised with an overdose of sodium pentobarbital (200 mg/kg; cat. no. B1202-005; Fluka), and a U-shaped incision was made to open the abdominal cavity. The degree of abdominal adhesion was scored as follows: Grade 0, no adhesions (5 points); grade 1, thin filmy adhesion (4 points); grade 2 , thick adhesions in a limited area (3 points); grade 3 , widespread adhesions ( 2 points); and grade 4 , widespread adhesions plus adherence of visceral organs to the abdominal wall (1 point). Tissue was collected from the typical abdominal adhesion site or intestinal tissue from the modelling site, and specimens were stored in $4 \%$ paraformaldehyde in preparation for hematoxylin and eosin (H\&E) staining and Masson staining. Venous blood was obtained from the inferior vena cava of rats, centrifuged at $1,000 \mathrm{x} g$ for $20 \mathrm{~min}$ at $4^{\circ} \mathrm{C}$, and then the supernatant was carefully removed and stored at $-80^{\circ} \mathrm{C}$. Rat faeces were stored in glycerol and maintained in a refrigerator at $-80^{\circ} \mathrm{C}$ for later use.

$H \& E$ and Masson staining. Adhered tissues or intestinal tissue were fixed in $4 \%$ paraformaldehyde at $4^{\circ} \mathrm{C}$ for $24 \mathrm{~h}$ and then embedded in paraffin. The samples were cut into sections of 5-6 $\mu \mathrm{m}$ thickness and then rehydrated with xylene and declining grades of ethanol for 5-6 min. Specimens were washed three times with PBS for another $5 \mathrm{~min}$, then H\&E and Masson staining were performed (29).

$R N A$ preparation and quantitative PCR. For the evaluation of cytokine mRNA expression levels of IL- $1 \beta$, IL- 6 and TNF- $\alpha$, total RNA from adhered tissues or intestinal tissue were prepared by adding TRIzol reagent (Gibco BRL; Thermo Fisher Scientific, Inc.) according to the manufacturer's protocol (30). 
In addition, the purity and integrity of RNA were evaluated using a NanoDrop 2000 spectrophotometer (Thermo Fisher Scientific, Inc.). RNA (1 mg) was reversed-transcribed into cDNA using the PrimeScript RT Master Mix reverse transcription kit (Takara Biotechnology Co., Ltd.). Quantitative real-time PCR was performed using a $7900 \mathrm{HT}$ fast real-time PCR system (ABI; Thermo Fisher Scientific, Inc.) using 2X SYBR-Green Master Mix (Bio-Rad Laboratories, Inc.). Forty cycles at $95^{\circ} \mathrm{C}$ for $30 \mathrm{sec}$ and $60^{\circ} \mathrm{C}$ for $30 \mathrm{sec}$ were conducted, preceded by $1 \mathrm{~min}$ at $95^{\circ} \mathrm{C}$. The following primers were used: IL-1 $\beta$ sense, 5'-GTGTCTTTCCCGTGGACCTTC-3' and antisense, 5'-TCATCTCGGAGCCTGTAGTGC-3'; TNF- $\alpha$ sense, 5'-GTGGAACTGGCAGAAGAGGCA-3' and antisense, 5'-AGAGGGAGGCCATTTGGGAAC-3'; IL-6 sense, 5'-GAAATCGTGGAAATGAG-3' and antisense, 5'-GCTTAG GCATAACGCACT-3'; and GAPDH sense, 5'-CTCGTGGAG TCTACTGGTGT-3' and antisense 5'-GTCATCATACTTGGC AGGTT-3'.

Measurement of cytokines. Venous blood was obtained from the inferior vena cava of rats, and then centrifuged at $1,000 \mathrm{x} \mathrm{g}$ for $20 \mathrm{~min}$ at $4^{\circ} \mathrm{C}$. The concentrations of cytokines IL-1 $\beta$ (cat. no. RK00009; rat; ABclonal, Inc.; detection range, 62.5-4000 pg/ml; concentrations used for generating calibration curves: 4000, 2000, 1,000, 500, 250, 125, 62.5, 31.2 and 0 pg/ml), IL-6 (cat. no. RK00020; rat; ABclonal, Inc.; detection range, $125-8000 \mathrm{pg} / \mathrm{ml}$; concentrations used for generating calibration curves: 4000, 2000, 1,000, 500, 250, 125, 62.5 and $0 \mathrm{pg} / \mathrm{ml}$ ) and TNF- $\alpha$ (cat. no. RK00029; rat; ABclonal, Inc.; detection range, 62.5-4000 pg/ml; concentrations used for generating calibration curves: 2000, 1,000, 500, 250, 125, 62.5, 31.2 and $0 \mathrm{pg} / \mathrm{ml}$ ) in rat venous blood serum were measured using enzyme-linked immunosorbent assay (ELISA) kits according to the manufacturer's protocol.

Western blot analysis. Intestinal samples were extracted using Cell Lysis buffer (cat. no. R0020; Solarbio, Inc.) supplemented with protease inhibitor cocktail (cat. no. 78429) and $1 \mathrm{mM}$ phenylmethanesulfonyl fluoride (PMSF) (cat. no. 36978; both from Thermo Fisher Scientific, Inc.). The protein concentration was determined using a BCA protein assay kit. After degeneration, proteins were separated using $10 \%$ polyacrylamide resolving gels and then transferred onto polyvinylidene fluoride (PVDF) membranes. Protein concentrations were mixed and then resolved by polyacrylamide gel electrophoresis. Nonspecific binding sites were blocked using 5\% skim milk with Tris-buffered saline with Tween-20 (TBST) for $90 \mathrm{~min}$ at room temperature (RT). Then, membranes were co-incubated overnight at $4^{\circ} \mathrm{C}$ with the following primary antibodies: Mouse anti- $\beta$-actin (1:5,000; cat. no. 60008-1-Ig; ProteinTech Group, Inc.; RRID: AB_2289225; having reactivity with rat), mouse anti-TLR4(1:750; cat.no.sc-293072; Santa Cruz Biotechnology, Inc.; RRID: AB_10611320; having reactivity with rat), and rabbit anti-myeloid differentiation primary response 88 (MyD88; 1:1,000; cat. no. A0980; ABclonal, Inc.; RRID: AB_2722690; having reactivity with rat), rabbit anti-NF- $\kappa$ B p65 (1:2,000; cat. no. 10745-1-AP; ProteinTech Group, Inc.; RRID: AB_2178878; having reactivity with rat), rabbit anti-phosphorylated (p)-NF-кB p65 (1:1,000; cat. no. 3033; Cell Signaling Technology, Inc.; RRID: AB_331284; having reactivity with rat), rabbit anti-TGF- $\beta 1(1: 1,000$; cat. no. 21898-1-AP; ProteinTech Group, Inc.; RRID: Not registered; having reactivity with rat), rabbit anti-p-Smad2 (1:1,000; cat. no. 18338; Cell Signaling Technology, Inc.; RRID: AB_2798798; having reactivity with rat), rabbit anti-Smad2 (1:1,000; cat. no. A11498; ABclonal, Inc.; RRID: AB_2758585; having reactivity with rat), rabbit anti-p-Smad3 (1:1,000; cat. no. 9520; Cell Signaling Technology, Inc.; RRID: AB_2193207; having reactivity with rat), rabbit anti-Smad3 (1:1,000; cat. no. A7536; ABclonal, Inc.; RRID: AB_2768063; having reactivity with rat), and rabbit anti-alpha smooth muscle actin ( $\alpha$-SMA; $1: 1,000$; cat. no. A1011; ABclonal, Inc.; RRID: AB_2757633; having reactivity with rat). After primary incubation, the membranes were washed with TBST buffer three times for $10 \mathrm{~min}$ each, then incubated with goat anti-rabbit secondary antibody (1:5,000; cat. no. SA00001-2; ProteinTech Group, Inc.; RRID: AB_2722564) or goat anti-mouse secondary antibody (1:5,000; cat. no. SA00001-1; ProteinTech Group, Inc.; RRID: AB_2722565) to bind with horseradish peroxidase (HRP) for $60 \mathrm{~min}$ at RT. Finally, the proteins were visualised using enhanced chemiluminescence (ECL Western blot kit; cat. no. CW0049S; CwbioTech, Inc.) $(31,32)$. Densitometry was performed using Image Lab Software (version 4.0; Bio-Rad Laboratories, Inc.).

Total bacterial genomic DNA extraction and high-throughput sequencing. For microbial DNA extraction, rat faecal samples for the C $(n=8), M(n=8), T(n=8)$ and PT $(n=8)$ groups were collected. The bead-beating method was combined with genomic DNA kits (Tiangen Biotech Co., Ltd.), and a spectrophotometer (NanoDrop; Thermo Fisher Scientific, Inc.) was used to determine the concentration and quality of purified DNA. Then, 515F/806R primers (515F, 5'-GCACCTAAY TGGGYDTAAAGNG-3'; 806R, 5'-TACNVGGGTATCTAA TCC-3') were used to amplify the V4 region of the 16S rDNA genes in each sample. These PCR products were sequenced with an IlluminaHiSeq 2000 platform (GenBank accession no. PRJNA542549) (33).

Data analysis. To analyse the high-throughput sequencing data, Cutadapt (version 1.9.1, http://cutadapt.readthedocs. io/en/stable/), UCHIME algorithm http://www.drive5. com/usearch/manual/uchime_algo.html, UPARSE software package (version 7.0.100), QIIME software (version 1.9.1), QIIME software package (version 1.8.0) and SIMCA-P software (version 11.5; Umetrics; Sartorius Stedim) were used to determine the $\alpha$ diversity (within a sample) and $\beta$ diversity (among samples) (34,35).

Statistical analyses were performed using Prism software (version 7.0; GraphPad Software, Inc.). Data are presented as the means \pm standard deviation (SD). Statistical significance was determined using one-way analysis of variance (ANOVA) followed by Tukey's multiple comparison test. Error probabilities of $\mathrm{P}<0.05$ were considered to indicate a statistically significant difference.

\section{Results}

Probiotic combinations prevent and treat abdominal adhesions. During the model development process, two rats in 

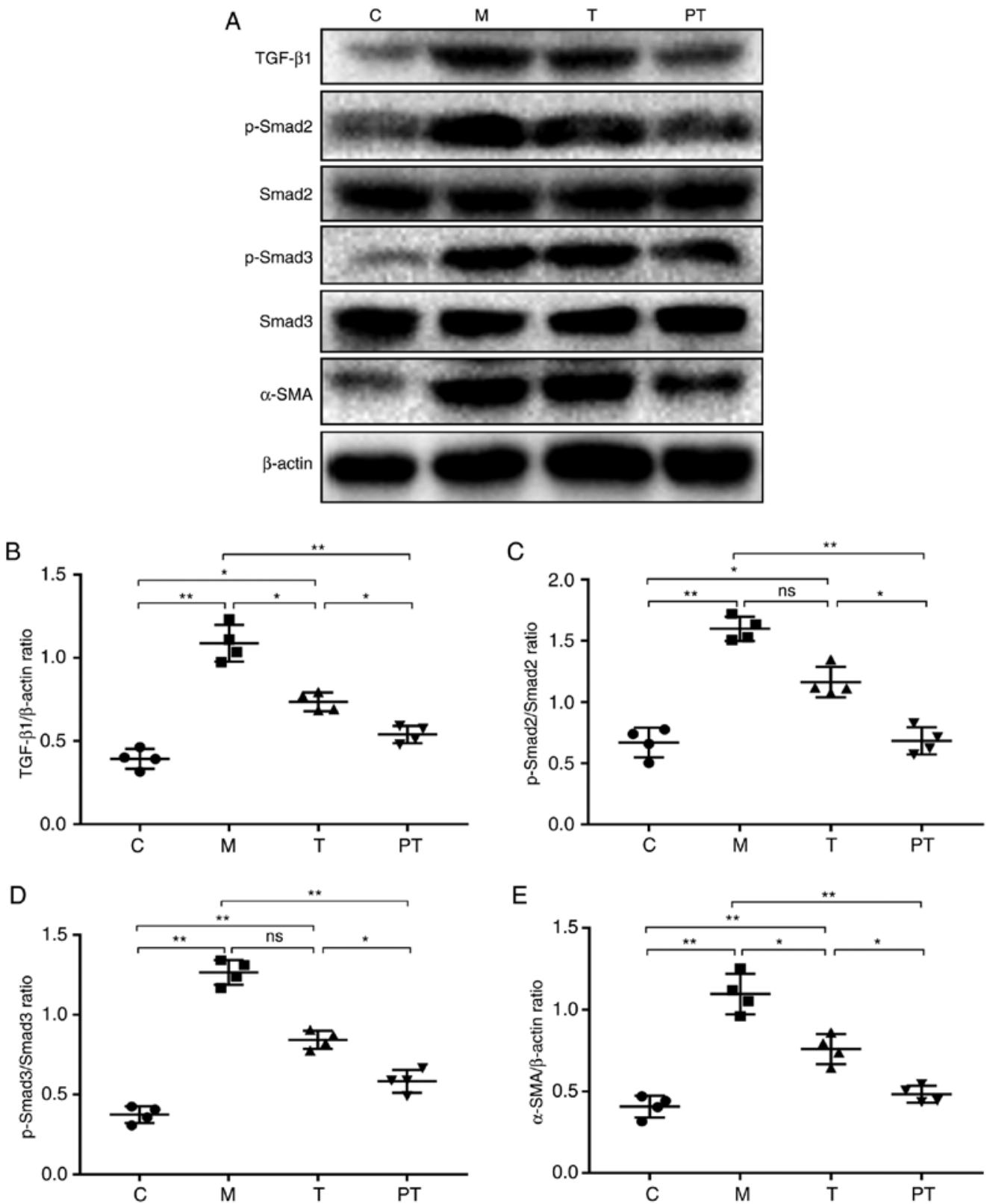

Figure 2. Effect of probiotics on the expression of proteins associated with the TGF- $\beta 1 /$ Smad signalling pathway in vivo. (A) Expression of fibrotic-related proteins in rat small intestine tissue, revealing that the combination of probiotics significantly downregulated the TGF- $\beta 1 /$ Smad signalling pathway at the protein level. (B) Expression of fibrotic-related TGF- $\beta 1$ protein in rat small intestine tissue $(n=4)$. (C) Effect of the probiotic combinations on fibrotic-related $\mathrm{p}$-Smad2/Smad2 proteins in rat small intestine tissue $(\mathrm{n}=4)$. (D) Effect of the probiotic combinations on fibrotic-related p-Smad3/Smad3 proteins in rat small intestine tissue $(n=4)$. (E) Effect of the probiotic combinations on fibrotic-related $\alpha$-SMA protein in rat small intestine tissue ( $n=4)$. C, control group; $\mathrm{M}$, model group; T, treatment group (fed $10^{9} \mathrm{CFU}$ probiotic combinations 7 days after remodelling); PT, prevention and treatment group (fed $10^{9} \mathrm{CFU}$ probiotic combinations 3 days before remodelling). Data are presented as the means \pm SD. $n s, P>0.05 ;{ }^{*} \mathrm{P}<0.05 ;{ }^{* * *} \mathrm{P}<0.01$. TGF- $\beta 1$, transforming growth factor- $\beta 1$; $\alpha$-SMA, $\alpha$-smooth muscle actin.

the M, T and PT groups respectively died of surgery-related causes within $24 \mathrm{~h}$, and no abdominal wall dehiscence or bowel perforation were found in these animals (data not shown). As revealed in Fig. 1B, there was a significant reduction in the body weight of rats in the $\mathrm{M}$ group after surgery, while rats treated with probiotics, especially those in the PT group, had increased body weight compared with rats in the $\mathrm{M}$ group $(\mathrm{P}<0.05)$. The degree of abdominal adhesion was compared using the abdominal adhesion score, and it was revealed that surgery significantly reduced the degree of abdominal adhesion in group $\mathrm{M}$ compared to group $\mathrm{C}$ (3.24 vs. 5.0, $\mathrm{P}<0.01$ ). The groups treated with probiotics exhibited a significantly improved abdominal adhesion score compared with the $\mathrm{M}$ group ( $\mathrm{T}$ group, 4.2 vs. 3.24, $\mathrm{P}<0.05$; PT group, 4.8 vs. $3.24, \mathrm{P}<0.05$; Fig. $1 \mathrm{C})$. $\mathrm{H} \& \mathrm{E}$ and Masson staining further demonstrated that probiotics reduced inflammatory cell infiltration, the production of collagenous fibres caused by surgery and intestinal villus destruction compared with the M group (Fig. 1D).

Probiotic combinations reduce fibrosis. The formation of adhesions is closely related to the TGF- $\beta 1 /$ Smad signalling pathway; therefore, the level of their expression at the adhesion site was evaluated. As revealed in Fig. 2, surgery led to a 

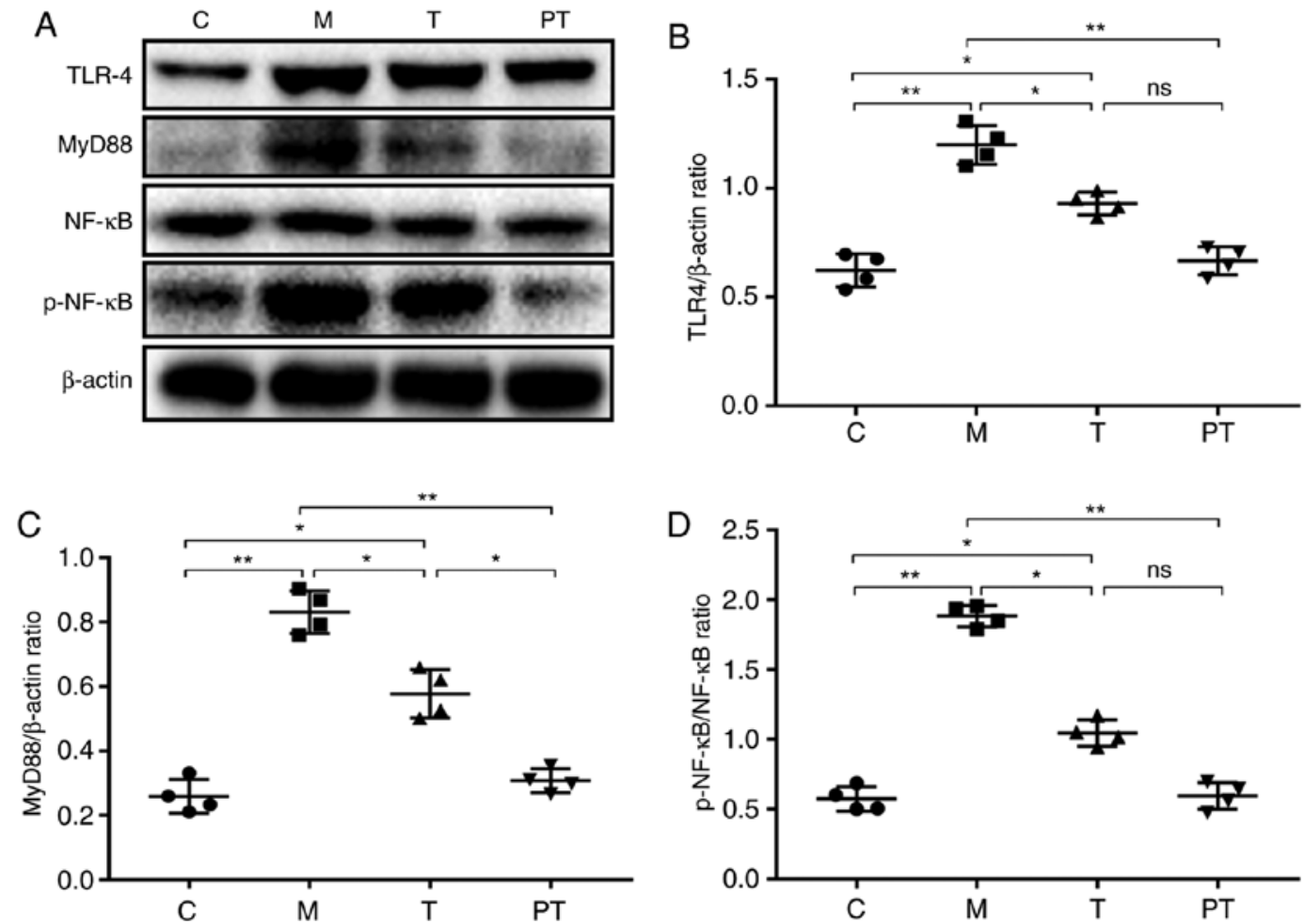

Figure 3. Effect of probiotics on the expression of proteins related to the TLR4/NF- $\mathrm{B}$ signalling pathway in vivo. (A) Expression of inflammation-related proteins in rat small intestine tissue, revealing that the combination of probiotics significantly downregulated the key proteins of the TLR4/NF- $\mathrm{B}$ signalling pathway at the protein level. (B) Effect of the probiotic combinations on inflammation-related TLR4 protein in rat small intestine tissue (n=4). (C) Effect of the probiotic combinations on inflammation-related MyD88 protein in rat small intestine tissue (n=4). (D) Effect of the probiotic combinations on inflammation-related $\mathrm{p}-\mathrm{NF}-\kappa \mathrm{B} / \mathrm{NF}-\kappa \mathrm{B}$ proteins in rat small intestine tissue $(\mathrm{n}=4)$. C, control group; $\mathrm{M}$, model group; T, treatment group (fed $10^{9} \mathrm{CFU}$ probiotic combinations 7 days after remodelling); PT, prevention and treatment group (fed $10^{9} \mathrm{CFU}$ probiotic combinations 3 days before remodelling). Data are presented as the means \pm SD. ns, $\mathrm{P}>0.05 ;{ }^{*} \mathrm{P}<0.05 ;{ }^{* *} \mathrm{P}<0.01$. TLR4, Toll-like receptor 4 ; NF- $\kappa \mathrm{B}$, nuclear factor- $\kappa \mathrm{B}$; MyD88, myeloid differentiation primary response 88 .

significant increase in the expression of TGF- $\beta 1(0.39$ vs. 1.09 , $\mathrm{P}<0.01)$, p-Smad2 (0.71 vs. $1.54, \mathrm{P}<0.01)$ and $\mathrm{p}-\mathrm{Smad} 3$ ( 0.37 vs. $1.27, \mathrm{P}<0.01)$ compared with the control group, but treatment with probiotics reversed this trend and recovered the TGF- $\beta 1, \mathrm{p}-\mathrm{Smad} 2$ and $\mathrm{p}-\mathrm{Smad} 3$ expression levels in the $\mathrm{T}$ group to $0.74,1.22$ and 0.84 and in the PT group to 0.54 , 0.66 and 0.58 , respectively. The expression of the myofibroblast marker $\alpha$-SMA was then studied, and it was revealed that probiotics inhibited the formation of fibres caused by surgery. In the PT group, probiotic treatment reduced the $\alpha$-SMA expression compared with the $\mathrm{M}$ group (0.48 vs. $1.09 ; \mathrm{P}<0.01)$.

Probiotic combinations decrease the concentration of inflammatory mediators. To verify whether the occurrence of abdominal adhesion was related to inflammation, the classical inflammatory TLR4/NF- $\kappa$ B signalling pathway was investigated using western blotting, and it was revealed that surgery significantly upregulated the expression of TLR4 (0.62 vs. 1.20, $\mathrm{P}<0.01)$, MyD88 (0.26 vs. 0.83, $\mathrm{P}<0.01)$ and $\mathrm{p}-\mathrm{NF}-\kappa \mathrm{B} / \mathrm{NF}-\kappa \mathrm{B}$ (0.57 vs. $1.88, \mathrm{P}<0.01)$ compared with the $\mathrm{C}$ group, and the probiotic combinations administered to the $\mathrm{T}$ and $\mathrm{PT}$ groups significantly reduced the TLR4, MyD88 and p-NF- $\mathrm{BB}$ expression levels to $0.93,0.58$ and 1.05 for the $\mathrm{T}$ group and $0.67,0.31$ and 0.59 for the PT group, respectively (Fig. 3).

It is known that activation of the TLR4/NF- $\kappa \mathrm{B}$ signalling pathway causes the release of proinflammatory factors; therefore, the effect of the probiotic combinations on the release of inflammatory factors at the gene (q-PCR) and protein (ELISA) levels, were investigated. Surgery significantly enhanced the transcriptional levels of IL-1 $\beta$ (1.00 vs. $3.42, \mathrm{P}<0.05)$, IL-6 $(1.00$ vs. $3.23, \mathrm{P}<0.05)$ and TNF- $\alpha(1.00$ vs. $2.91, \mathrm{P}<0.05)$ in the $\mathrm{M}$ group compared with the $\mathrm{C}$ group, and administration of probiotics significantly reduced the expression of the proinflammatory factors IL-1 $\beta$, IL-6 and TNF- $\alpha$ to $2.04,2.77$ and 2.08 in the T group and 1.46, 1.03 and 1.16 in the PT group, respectively. Likewise, the ELISA results supported the finding that probiotics significantly inhibited the production of proinflammatory factors in rat blood, with decreasing levels of IL-1 $\beta$, IL- 6 and TNF- $\alpha$ from 1081, 360 and 136 in the M group, respectively, to 826, 293 and 102 in the T group $(\mathrm{P}<0.05)$ and 649, 265 and 91 in the PT group ( $<<0.01)$, respectively (Fig. 4).

\section{Probiotic combinations restore the intestinal microbiota} to a normal state. The intestinal microbiota is associated with many intestinal diseases, including intestinal fibrosis. High-throughput sequencing indicated that surgery significantly disturbed the microbial balance, and reduced the Shannon diversity, the richness of the microbiome $(\mathrm{P}<0.05)$ and the abundance-based coverage estimators (ACE) index $(\mathrm{P}<0.01)$, although small statistical differences were observed among these 3 indexes due to their different statistical approaches (Fig. 5A-C). However, administration of probiotics in the $\mathrm{T}$ and $\mathrm{PT}$ groups recovered the relative abundance of microbiota to normal levels $(\mathrm{P}<0.05)$. In addition, the 
A

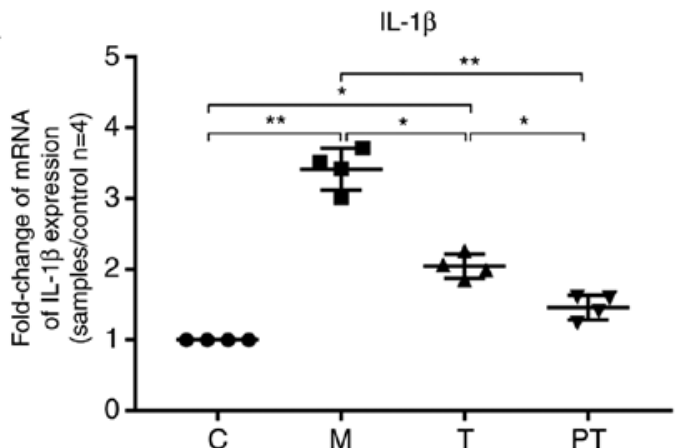

C

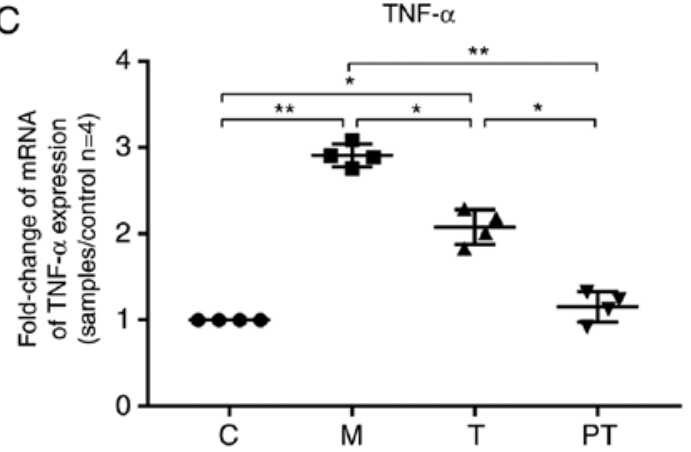

E

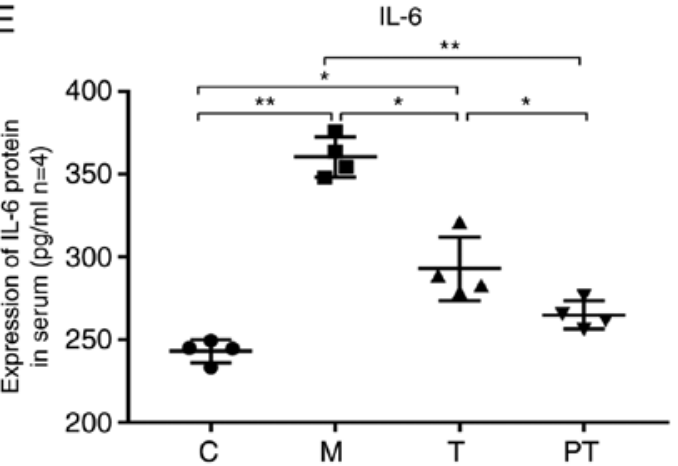

B
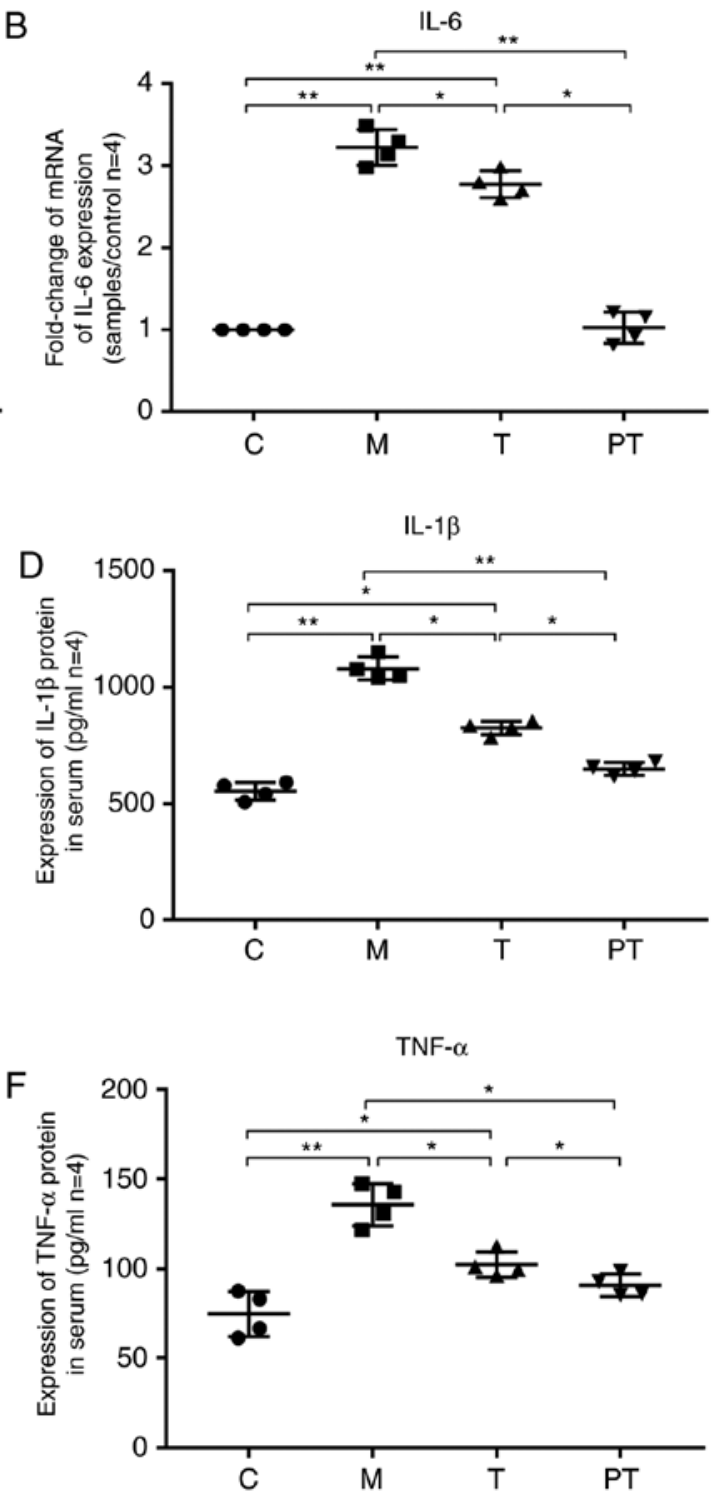

Figure 4. Inhibitory effect of probiotics on the expression of inflammatory mediators at the gene and protein levels. (A-C) Inhibitory effect of the probiotic combinations on the expression of IL-1 $\beta$, IL-6 and TNF- $\alpha$ in small intestinal tissue of rats at the gene level (n=4). (D-F) Inhibitory effect of the probiotic combinations on the expression of IL-1 $\beta$, IL- 6 and TNF- $\alpha$ in the serum of rats at the protein level ( $n=4)$. C, control group; M, model group; T, treatment group (fed $10^{9} \mathrm{CFU}$ probiotic combinations 7 days after remodelling); PT, prevention and treatment group (fed $10^{9} \mathrm{CFU}$ probiotic combinations 3 days before remodelling). Data are presented as the means \pm SD. ${ }^{*} \mathrm{P}<0.05 ;{ }^{* *} \mathrm{P}<0.01$. IL, interleukin; TNF- $\alpha$, tumour necrosis factor- $\alpha$.

principal coordinate analysis ( $\mathrm{PCOA})$ confirmed that the intestinal microbiota in the $\mathrm{M}$ group were located far away from the $\mathrm{C}$ group, and the $\mathrm{C}, \mathrm{T}$ and $\mathrm{PT}$ groups were close to each other in distance (Fig. 5D). At the order level (Fig. 5E), communities of gut microbiota in the $\mathrm{M}$ group exhibited a decrease in Bacteroidales (0.45 vs. 0.25$)$ and Lactobacillales ( 0.20 vs. 0.16$)$, but exhibited an increase in Clostridiales (0.27 vs. 0.37 ) and Coriobacteriales (0.045 vs. 0.036$)$ when compared with rats in the $\mathrm{C}$ group. However, it was determined that supplementation with the probiotic combinations altered the relative abundance of Bacteroidales (0.29 vs. 0.27), Lactobacillales (0.27 vs. 0.35), Clostridiales (0.30 vs. 0.28) and Coriobacteriales (0.025 vs. 0.013$)$ in the $\mathrm{T}$ group and PT group. At the genus level, similar with the aforementioned results, supplementation of probiotics significantly changed the composition of intestinal microorganisms, greatly enhanced the richness of Lactobacillus (levels in the C, M, T and PT groups were $0.19,0.15,0.25$ and 0.34 , respectively), Ruminococcus $(0.033,0.012,0.015$ and 0.030 , respectively), while the relative levels of Oscillospira (0.041, $0.061,0.035$ and 0.045 , respectively) were markedly decreased (Fig. 5F).

In order to further analyse intestinal microorganisms in rats, the relative abundance of some probiotic bacteria as well as pathogens that were closely associated with intestinal diseases were compared. The results revealed that surgery tended to decrease the relative abundance of Bacteroidetes, but increase the abundance of Firmicutes and Proteobacteria $(\mathrm{P}<0.05)$ at the phylum level (Fig. 6A-C). At the order level, communities of gut microbiota in the $\mathbf{M}$ group exhibited a decrease in Bacteroidales ( 0.45 vs. 0.25 ) and Lactobacillales ( 0.20 vs. 0.16 ) but an increase in Erysipelotrichales (0.0075 vs. 0.034) and Verrucomicrobiales (0.0022 vs. 0.0198) levels compared with $\mathrm{C}$ group ( $\mathrm{P}<0.05$; Fig. 6D-G), while the probiotic combinations administered to the $\mathrm{T}$ and $\mathrm{PT}$ groups significantly increased 

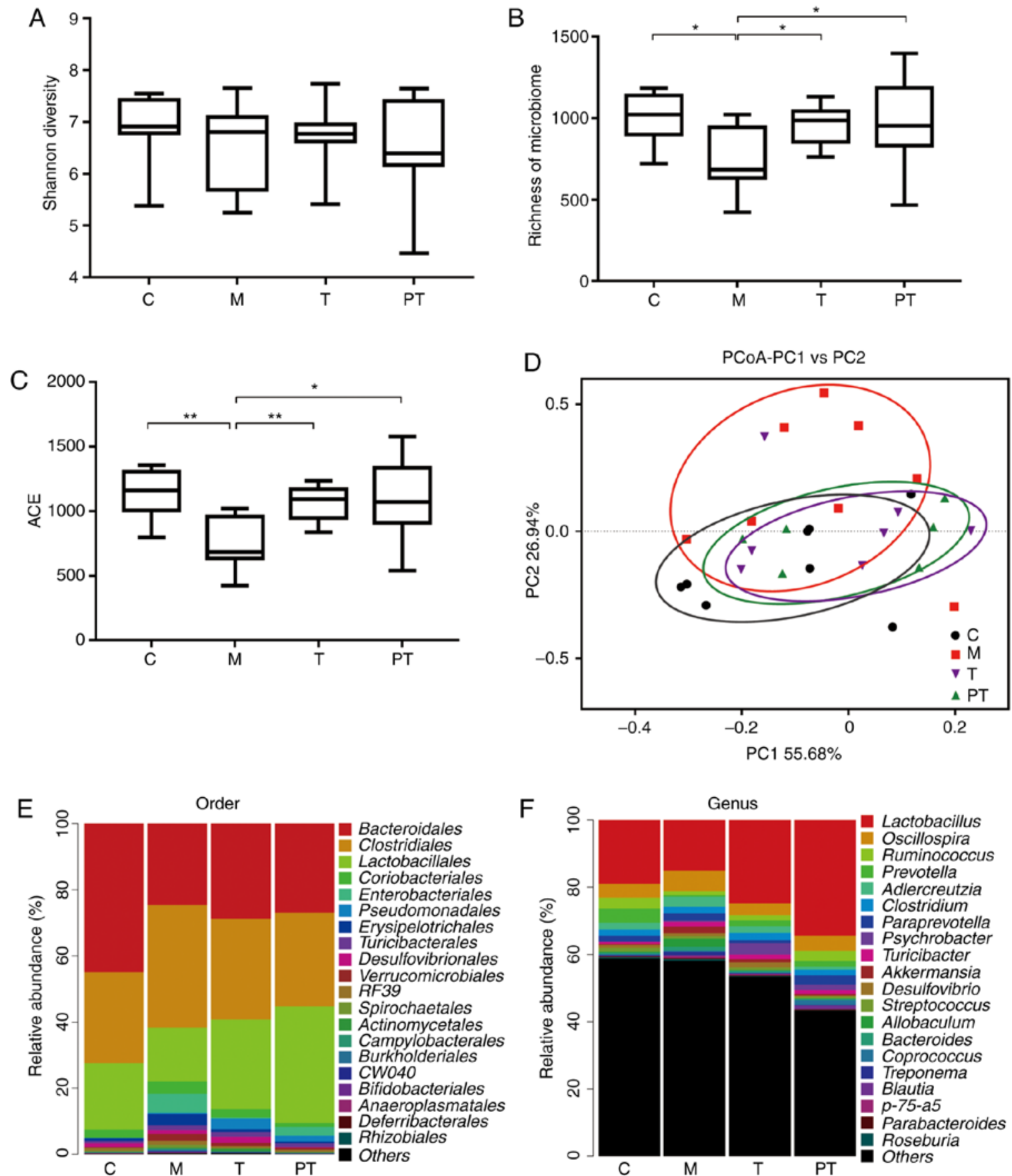

Figure 5. Evaluation of the overall effect of the probiotic combinations on microorganisms in rat faeces, determined using high-throughput sequencing technology. Evaluation of the effect of the probiotic combinations on intestinal microbiota regarding (A) the Shannon Diversity, (B) the richness of the microbiome, (C) the ACE index, (D) the PCoA of the $\beta$ diversity index. Effect of the probiotic combinations on intestinal microorganisms regarding the relative abundance (E) at the order level and (F) at the genus level. $(\mathrm{n}=8)$. C, control group; $\mathrm{M}$, model group; $\mathrm{T}$, treatment group (fed $10^{9} \mathrm{CFU}$ probiotic combinations 7 days after remodelling); PT, prevention and treatment group (fed $10^{9} \mathrm{CFU}$ probiotic combinations 3 days before remodelling). Data are presented as the means $\pm \mathrm{SD}$. ${ }^{*} \mathrm{P}<0.05 ;{ }^{* *} \mathrm{P}<0.01$. ACE, abundance-based coverage estimators; PCoA, principal coordinate analysis.

Bacteroidales (0.29vs. 0.27) and Lactobacillales (0.27 vs. 0.35) and decreased Erysipelotrichales (0.0074 vs. 0.0095) and Verrucomicrobiales (0.0095 vs. 0.0053). At the genus level (Fig. 6H-K), it was observed that surgery markedly reduced the richness of beneficial bacteria Lactobacillus (0.19 vs. $0.15 \%$ ) and Anaerostipes ( 0.028 vs. $0.001 \%$ ), but enhanced the abundance of pathogenic bacteria Klebsiella ( 0 vs. $0.44 \%$ ) and Serratia (0 vs. $0.075 \%$ ) compared with the $\mathrm{C}$ group $(\mathrm{P}<0.05)$. Supplementation of the probiotic combinations significantly reversed this trend, with $\mathrm{T}$ and PT groups exhibiting a similar abundance of Lactobacillus ( 0.25 vs. $0.34 \%$ ), Anaerostipes (0.009 vs. $0.013 \%)$, Klebsiella (0.003 vs. $0.002 \%)$ and Serratia (0.003 vs. $0 \%$ ) to controls.

\section{Discussion}

Although the mechanism underlying abdominal adhesion formation has not yet been completely elucidated, the general assumption is that they develop through processes related to healing after injury (36). Briefly, abdominal adhesions can be 

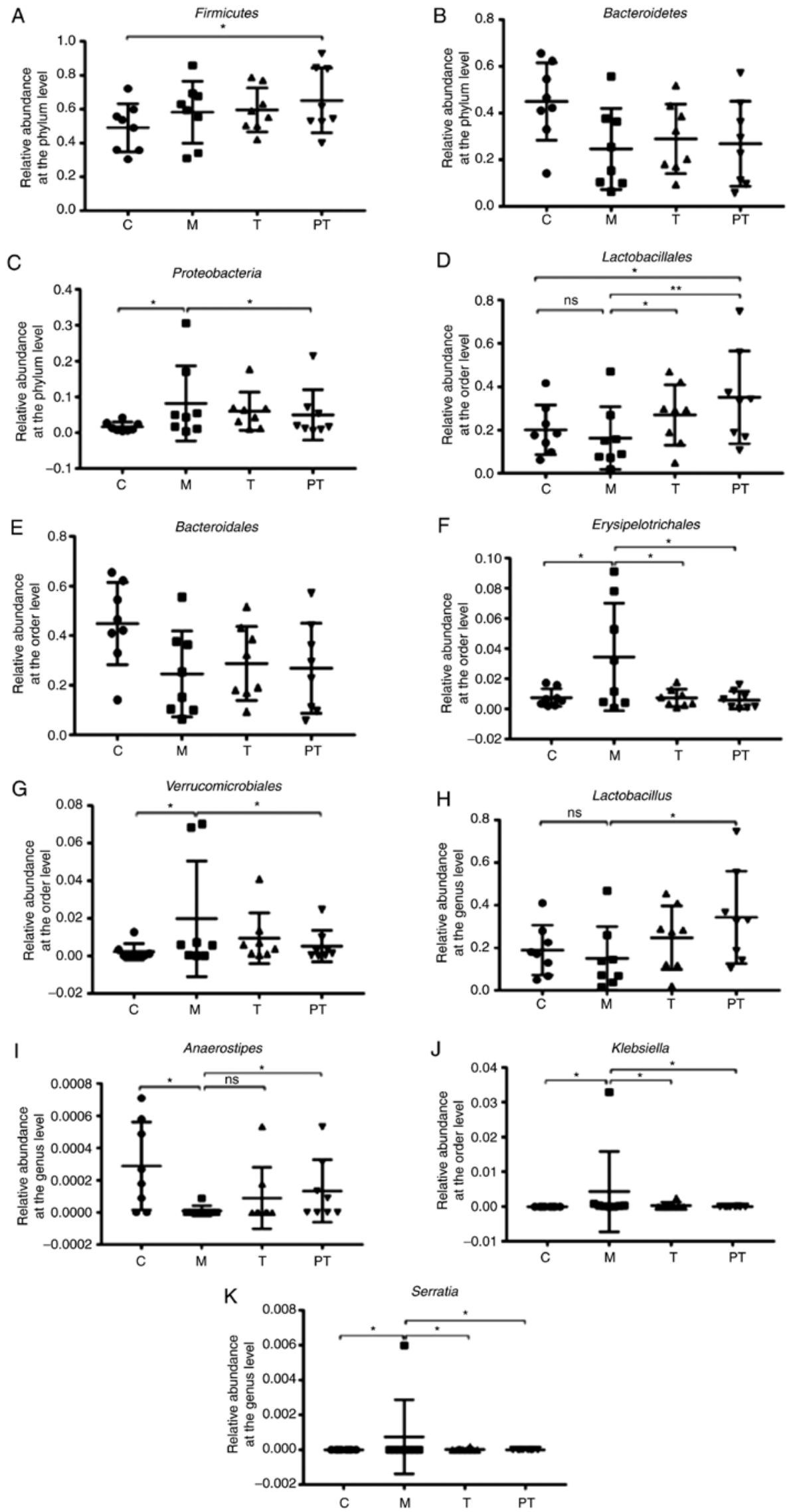

Figure 6. Composition and relative abundance of intestinal flora in rat faeces by phylum, order and genus, determined using high-throughput sequencing technology. Evaluation of the effect of the probiotic combinations on the relative abundance of phyla (A) Firmicutes, (B) Bacteroidetes (C) and Proteobacteria $(\mathrm{n}=8)$. Evaluation of the effect of the probiotic combinations on the relative abundance of orders (D) Lactobacillales, (E) Bacteroidales, (F) Erysipelotrichales and (G) Verrucomicrobiales $(\mathrm{n}=8)$. Evaluation of the effect of the probiotic combinations on the relative abundance of genera (H) Lactobacillus, (I) Anaerostipes, (J) Serratia and (K) Klebsiella $(\mathrm{n}=8)$. C, control group; $\mathrm{M}$, model group; $\mathrm{T}$, treatment group (fed $10^{9} \mathrm{CFU}$ probiotic combinations 7 days after remodelling); PT, prevention and treatment group (fed $10^{9} \mathrm{CFU}$ probiotic combinations 3 days before remodelling). Data are presented as the means $\pm \mathrm{SD}$. ns, $\mathrm{P}>0.05 ;{ }^{*} \mathrm{P}<0.05 ;{ }^{* *} \mathrm{P}<0.01$. 


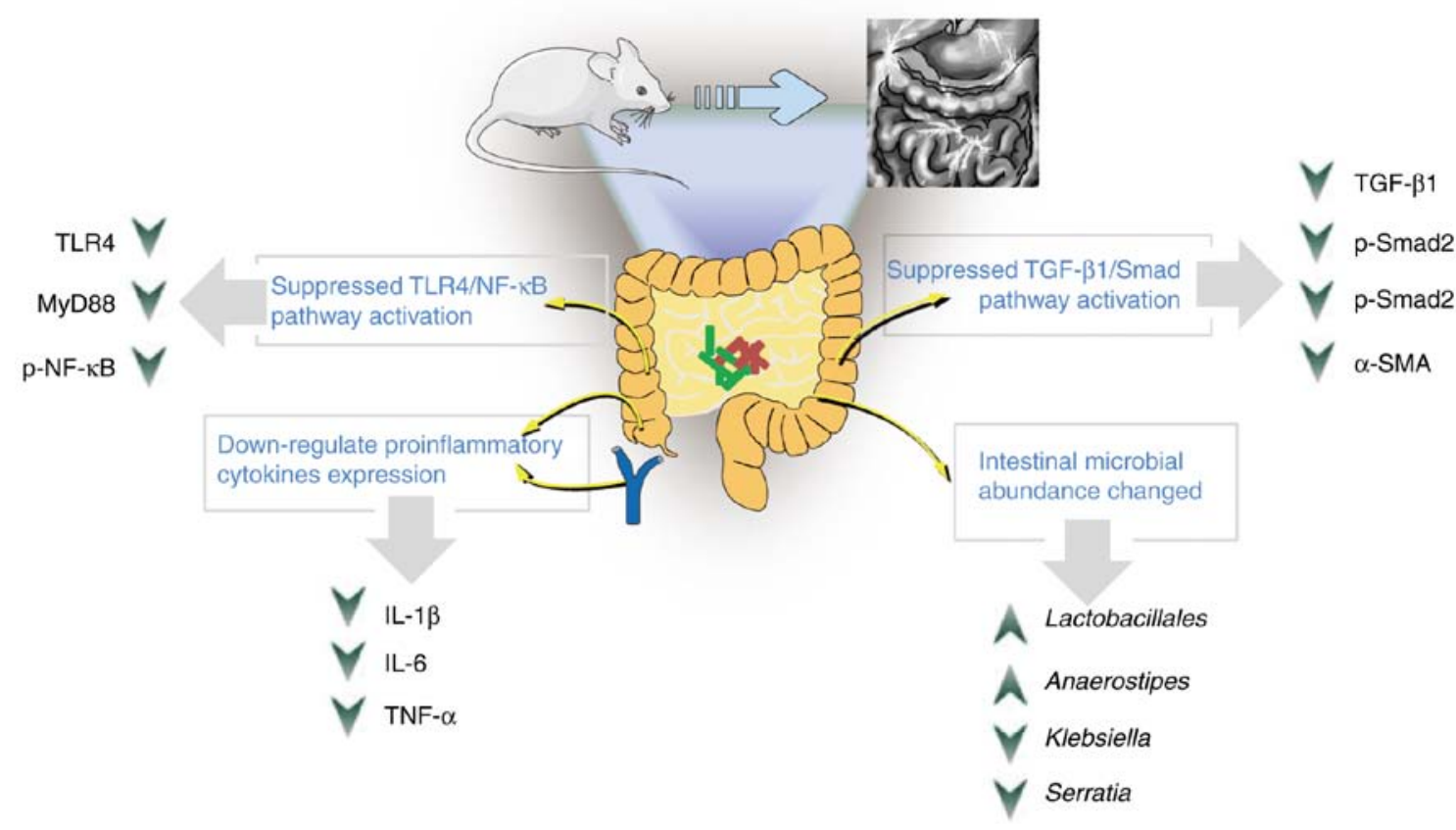

Figure 7. The potential mechanisms of probiotic combinations on abdominal adhesion.

attributed to inflammation caused by peritoneal stimulation, traction, drying and the introduction of foreign bodies during abdominal surgery. With inflammation which will initiate tissue repairing, during this repairing process, fibrin formation and dissolution are out of balance, collagen is deposited and, consequently, inappropriate adhesion occurs (37). Although researchers have been trying to solve this problem for a long time, the current interventions still have little effect.

The human intestinal tract is occupied by a large number of microorganisms which are commonly referred to as the intestinal microflora. This complex and dynamic bacterial community plays an important role in human health (38). Common probiotics include Lactobacillus, Bifidobacterium and some Escherichia coli.Lactobacillus and Bifidobacterium are vital members of the normal microflora of the gastrointestinal tract, and will accompany the host for a whole life. They contribute a great deal to maintaining the microbial balance of the body. In addition, they can stimulate the production of immunoglobulins, induce the expression of interferons in macrophages, and enhance the anti-inflammatory immunity of the host (39). A series of studies have reported that intestinal tract stimulation, intestinal tract preparation, use of preventive antibiotics and an imbalance in water and electrolytes after abdominal surgery may lead to disruptions in the intestinal microbial balance, resulting in endogenous infection and intestinal inflammation $(40,41)$. Accounts of probiotics inhibiting inflammatory processes are no longer unique, as there are numerous studies of their application in the treatment of ulcerative colitis, Crohn's disease, diarrhoea, constipation and even colorectal cancer $(18,19,26)$. However, the role of probiotics in the prevention of abdominal adhesions has not yet been studied. The occurrence and development of abdominal adhesions depend to a great extent on the inflammatory reaction of the damaged tissues (3). In the present study, attempts to prevent abdominal adhesions were made by administering a probiotic combination of Lactobacillus and Bifidobacterium (including L. plantarum, L. acidophilus, L. rhamnosus and B. animalis), since probiotic mixtures appear to exhibit greater efficacy than any single strain, although it is not clear whether this is attributable to synergism or is the consequence of the higher probiotic dose used in the studies investigating them.

Firstly, the effect of probiotics on the body weight and abdominal adhesion of rats following surgery were evaluated, and it was revealed that probiotics significantly increased their body weight when compared to the model group, and led to a significant reduction in the inflammatory cellular infiltration and fibrosis caused by surgery (Fig. 1). Notably, rats represented different scores in each groups due to individual differences (some people will not form abdominal adhesions after surgery in practice), and 1 rat in the $\mathbf{M}$ group had an abdominal adhesion score of 5, 4 rats had 4 points for the self-recovery capability of rats with not serious abdominal adhesion after the treatment stage. Numerous studies have revealed that TGF- $\beta 1 / \mathrm{Smad}$ signal transduction promotes fibroblast proliferation, the occurrence and development of fibrosis and adhesions, as well as the fibrosis in various tissues and organs, including renal, myocardial, liver and pulmonary fibrosis $(42,43)$. Most researchers maintain that TGF- $\beta$ is the initiating factor of fibrosis, and that it has a significant effect on the fibrosis of various tissues and organs. TGF- $\beta$ can activate fibroblasts to produce collagen, block plasminogen activator and disrupt the balance between fibrinolysis and synthesis, leading to extracellular matrix deposition and the formation of adhesions (17). TGF- $\beta 1$ has been revealed to be the most active cytokine in the TGF- $\beta$ family, and the level of TGF- $\beta 1$ increased gradually during the early postoperative period (15). Furthermore, Bi et al (44) revealed that TGF- $\beta 1$ was significantly upregulated in a mouse model of abdominal adhesions. In addition, the Smad signalling pathway is one of the major pathways by which members of the TGF- $\beta$ 
superfamily transmit signals through specific receptors on the cell membrane. Studies have revealed that TGF- $\beta 1$ could activate Smad3 to promote myocardial interstitial fibrosis, causing myocardial fibrosis and other irreversible changes, and eventually leading to chronic heart failure (45). Furthermore, research by Guo et al (46) revealed that downregulating the expression of Smad2/Smad3 markedly reduced the development of abdominal adhesions. The present study, confirmed that surgery increased fibrosis ( $\alpha$-SMA is a marker protein of myofibroblasts) in model rats, while the administration of probiotics observably reduced the levels of key proteins (TGF- $\beta 1$, p-Smad2, p-Smad 3 and $\alpha$-SMA) associated with the TGF- $\beta 1 /$ Smad pathway.

Inflammation plays an important role in various diseases, including abdominal adhesions $(3,47)$. Therefore, the effect of probiotics on the inflammatory state of rats was evaluated, and it was revealed that administration of probiotics significantly reduced the proinflammatory factors IL- $1 \beta$, IL- 6 and TNF- $\alpha$ and downregulated the TLR4/NF- $\kappa B$ inflammatory signalling pathway. The Toll-like receptor (TLR) family is one of the most characteristic pattern recognition receptor families, whose downstream molecules include NF- $\mathrm{BB}$ and MyD88. When a molecular pattern is recognised by TLRs, downstream signals are activated, leading to the release of a large amount of the proinflammatory factors TNF- $\alpha$ and IL-1 $\beta$ (48). Therefore, downregulating the expression of key proteins in the TLR4/NF- $\kappa B$ signalling pathway can reduce the inflammatory response. Studies have revealed that the expression levels of TLR4 and NF-kB are significantly upregulated when an inflammatory reaction occurs in the intestinal tract of mice, along with a marked increase in the release of related proinflammatory cytokines TNF- $\alpha$ and IL-6 (49). Research by Wei et al (47) demonstrated that downregulation of the NF-кB signalling pathway could observably reduce the inflammatory response and ultimately reduce abdominal adhesions. Therefore, the decreased expression of key proteins in the TLR4/NF- $\mathrm{kB}$ signalling pathway was observed in the groups receiving probiotics, which indicated that probiotics could prevent the occurrence of abdominal adhesions by suppressing inflammation.

Finally, the V4 hypervariable region of microbiota was sequenced using $16 \mathrm{~S}$ rRNA amplicon sequencing analysis, and the presence of intestinal microorganisms in rats was detected to further explore the mechanism underlying the protective effect of probiotics. The present results revealed that the combination of probiotics greatly enhanced the abundance of Lactobacillus and Anaerostipes, whereas it decreased the abundance of pathogenic Klebsiella and Serratia bacteria. As is known, Lactobacillus is often closely related to health. Studies have revealed that the abundance of Lactobacillus is significantly reduced in the intestinal tract of patients with irritable bowel syndrome (26). In addition, it has been reported that Anaerostipes can produce butyric acid, which plays a positive role in maintaining gastrointestinal health (50). A recent study by Wopereis et al (51) revealed that the abundance of the butyric acid-producing bacteria Anaerostipes was markedly decreased in infantile eczema. Klebsiella exists in the intestinal and respiratory tracts of humans, and can cause bronchitis, pneumonia, diarrhoea, urinary system infections and wound infection, and has even been linked to septicaemia, meningitis and peritonitis. A previous study revealed that the detection rate of Klebsiella pneumoniae was significantly increased in children with acute intestinal diseases, while the detection rate in healthy children without any clinical manifestations was relatively low (52). This indicates that Klebsiella has an aetiological relationship with acute bowel disease. Serratia is an important genus of Enterobacteriaceae that can cause hospital-related infections. It is invasive and resistant to numerous commonly used antibacterial drugs. In particular, Serratia marcescens has become an important conditioned pathogen, and has been identified as the main pathogen causing extraintestinal infection (53). In addition, a study revealed that the abundance of Serratia marcesens in patients with Crohn's disease was often higher than that in healthy family members, and these bacteria could cooperate with other pathogenic bacteria to aggravate intestinal inflammation (54).

The present study revealed that the probiotic combination administration was conducive to preventing abdominal adhesion by restoring microbial diversity and reducing inflammation and collagen deposition, and the effect was even more apparent when administered early (Fig. 7). Therefore, it is surmised, that in cases of extensive abdominal surgery, the administration of oral probiotic combinations during the perioperative period could have a positive effect on the prevention of abdominal adhesions. However, the present study was limited by the absence of an objective assessment tool for abdominal adhesions at the anatomical level in this animal model, and the discrepancies in the physiology and microbial composition between humans and rats. A clinical trial to assess these conclusions is required in the near future.

\section{Acknowledgements}

Not applicable.

\section{Funding}

This present study was supported by grants from the National Natural Science Foundation of China (81960103 to XD, 31560264 to TC), the Natural Science Foundation of Jiangxi province (20192ACBL20034 to ZL), the Excellent Youth Foundation of the Jiangxi Scientific Committee (20171BCB23028 to TC), the Science and Technology Plan of the Jiangxi Health Planning Committee (20175526 to TC), the Science and Technology Project of Jiangxi (20181BBG70028 and 20181BCB24003 both to TC).

\section{Availability of data and materials}

All data generated or analysed during this study are included in this published article.

\section{Authors' contributions}

TC, XD and ZL designed the experiments, analysed the data and wrote the manuscript. CZ, SW and RY performed the experiments. All authors discussed the results and commented on the final manuscript. All authors read and approved the manuscript and agree to be accountable for all aspects of the 
research in ensuring that the accuracy or integrity of any part of the work are appropriately investigated and resolved.

\section{Ethics approval and consent to participate}

The protocol was approved by the Committee on the Ethics of Animal Experiments of the Second Affiliated Hospital of Nanchang University (Jiangxi, China).

\section{Patient consent for publication}

Not applicable.

\section{Competing interests}

The authors declare that there are no competing interests regarding the publication of this study and regarding the funding that they have received.

\section{References}

1. Taylan E, Akdemir A, Ergenoglu AM, Yeniel AO and Tekindal MA: Can we predict the presence and severity of intra-abdominal adhesions before cesarean delivery. Gynecol Obstet Invest 82: 521-526, 2017.

2. Vrijland WW, Tseng LN, Eijkman HJ, Hop WC, Jakimowicz JJ, Leguit P, Stassen LP, Swank DJ, Haverlag R, Bonjer HJ and Jeekel H: Fewer intraperitoneal adhesions with use of hyaluronic acid-carboxymethylcellulose membrane: A randomized clinical trial. Ann Surg 235: 193-199, 2002.

3. Tsaousi G, Stavrou G, Fotiadis K, Kotzampassi K and Kolios G: Implementation of phospholipids as pharmacological modalities for postoperative adhesions prevention. Eur J Pharmacol 842 : 189-196, 2019.

4. Tanaka K, Hashimoto H, Misawa T and Akiba T: The prevention of carboxymethylcellulose on bowel adhesions induced by talc peritonitis in mice. J Surg Res 234: 311-316, 2019.

5. Bento SV, Nunes TA, Araujo ID, Silva RCOE, Vidigal PVT and Carvalhais RM: Hyperbaric oxygenation on adhesions prevention after laparotomy in rats. Acta Cir Bras 33: 824-833, 2018.

6. Robb WB and Mariette C: Strategies in the prevention of the formation of postoperative adhesions in digestive surgery: A systematic review of the literature. Dis Colon Rectum 57: 1228-1240, 2014.

7. Risberg B: Adhesions: Preventive strategies. Eur J Surg Suppl: 32-39, 1997.

8. Song Z, Zhang Y, Shao H, Ying Y, Chen X, Mei L, Ma X, Chen L, Ling $P$ and Liu F: Effect of xanthan gum on the prevention of intra-abdominal adhesion in rats. Int J Biol Macromol 126: 531-538, 2019.

9. Lin LX, Luo JW, Yuan F, Zhang HH, Ye CQ and Sun YL: In situ cross-linking carbodiimide-modified chitosan hydrogel for postoperative adhesion prevention in a rat model. Mat Sci Eng C Mater Biol Appl 81: 380-385, 2017.

10. Kuckelman J, Barron M, Kniery K, Kay J, Kononchik J, Hoffer Z and Sohn V: Crystalloid fluid suspension results in decreased adhesion burden when compared to bioresorbable membranes in a rat model. Am J Surg 217: 954-958, 2019.

11. Dinan TG and Cryan JF: The impact of gut microbiota on brain and behaviour: Implications for psychiatry. Curr Opin Clin Nutr Metab Care 18: 552-558, 2015.

12. Meng F, Chen T, Wang X, Wang X, Wei H, Tian P, Wang H, Zhao X, Shen L and Xin H: Evaluation of the accuracy and sensitivity of highthroughput sequencing technology using known microbiota. Mol Med Rep 17: 408-413, 2018.

13. Lee YK and Mazmanian SK: Has the microbiota played a critical role in the evolution of the adaptive immune system? Science 330: $1768-1773,2010$

14. Bing X, Xuelei L, Wanwei D, Linlang L and Keyan C: EGCG maintains $\mathrm{Th} 1 / \mathrm{Th} 2$ balance and mitigates ulcerative colitis induced by dextran sulfate sodium through TLR4/MyD88/NF- $\mathrm{BB}$ signaling pathway in rats. Can J Gastroenterol Hepatol 2017: 3057268,2017
15. Munireddy S, Kavalukas SL and Barbul A: Intra-abdominal healing: Gastrointestinal tract and adhesions. Surg Clin North Am 90: 1227-1236, 2010.

16. Duron JJ: Postoperative intraperitoneal adhesion pathophysiology. Colorectal Dis 9: 14-24, 2010.

17. Yao QY, Xu BL, Wang JY, Liu HC, Zhang SC and Tu CT: Inhibition by curcumin of multiple sites of the transforming growth factor-betal signalling pathway ameliorates the progression of liver fibrosis induced by carbon tetrachloride in rats. BMC Complement Altern Med 12: 156, 2012.

18. Tojo R, Suarez A, Clemente MG, de los Reyes-Gavilan CG, Margolles A, Gueimonde M and Ruas-Madiedo P: Intestinal microbiota in health and disease: Role of bifidobacteria in gut homeostasis. World J Gastroenterol 20: 15163-15176, 2014.

19. Nie P, Li Z, Wang Y, Zhang Y, Zhao M, Luo J, Du S, Deng Z, Chen J, Wang Y, et al: Gut microbiome interventions in human health and diseases. Med Res Rev 39: 2286-2313, 2019.

20. Fedorak RN, Feagan BG, Hotte N, Leddin D, Dieleman LA, Petrunia DM, Enns R, Bitton A, Chiba N, Paré P, et al: The probiotic VSL\#3 has anti-inflammatory effects and could reduce endoscopic recurrence after surgery for crohn's disease. Clin Gastroenterol Hepatol 13: 928-935, 2015.

21. Liu M, Zhang X, Hao Y, Ding J, Shen J, Xue Z, Qi W, Li Z, Song Y, Zhang $\mathrm{T}$ and Wang N: Protective effects of a novel probiotic strain, Lactococcus lactis ML2018, in colitis: In vivo and in vitro evidence. Food Funct 10: 1132-1145, 2019.

22. Munozprice LS, Lolans K and Quinn JP: Emergence of resistance to daptomycin during treatment of vancomycin-resistant enterococcus faecalis infection. Clin Infect Dis 41: 565-566, 2005.

23. Abdelkareem MZ, Sayed M, Hassuna NA, Mahmoud MS and Abdelwahab SF: Multi-Drug-Resistant enterococcus faecalis among Egyptian patients with urinary tract infection. J Chemother 29: 74-82, 2016.

24. Tuladhar R, Patole SK, Kon TH, Norton R and Whitehall JS: Refractory bacillus cereus infection in a neonate. Int $\mathrm{J}$ Clin Pract 54: 345-347, 2000.

25. Gröschel D, Burgress MA and Bodey GP Sr: Gas gangrene-like infection with bacillus cereus in a lymphoma patient. Cancer 37: 988-991, 2015

26. Heeney DD, Gareau MG and Marco ML: Intestinal Lactobacillus in health and disease, a driver or just along for the ride? Curr Opin Biotechnol 49: 140-147, 2018.

27. Hidalgo-Cantabrana C, Delgado S, Ruiz L, Ruas-Madiedo P, Sanchez B and Margolles A: Bifidobacteria and their health-promoting effects. Microbiol Spectr 5: 3, 2017.

28. Chen T, Wu Q, Li S, Xiong S, Wei H, Jiang S, Tan Q, Zhang Z and Zhu D: Microbiological quality and characteristics of probiotic products in China. J Sci Food Agric 94: 131-138, 2014.

29. Wang L, Yuan D, Zheng J, Wu X, Wang J, Liu X, He Y, Zhang C, Liu C, Wang T and Zhou Z: Chikusetsu saponin IVa attenuates isoprenaline-induced myocardial fibrosis in mice through activation autophagy mediated by AMPK/mTOR/ULK1 signaling. Phytomedicine 58: 152764, 2018.

30. Chen T, Tian P, Huang Z, Zhao X, Wang H, Xia C, Wang L and Wei H: Engineered commensal bacteria prevent systemic inflammation-induced memory impairment and amyloidogenesis via producing GLP-1. Appl Microbiol Biotechnol 102: 7565-7575, 2018.

31. Tian $\mathrm{P}, \mathrm{Xu} \mathrm{D}$, Huang $\mathrm{Z}$, Meng F, Fu J, Wei $\mathrm{H}$ and Chen $\mathrm{T}$ : Evaluation of truncated $\mathrm{g}$ protein delivered by live attenuated salmonella as a vaccine against respiratory syncytial virus. Microb Pathog 115: 299-303, 2018.

32. Fang $X$, Tian $P$, Zhao $X$, Jiang $C$ and Chen $T$ : Neuroprotective effects of an engineered commensal bacterium in the 1-methyl-4-phenyl-1, 2, 3, 6-tetrahydropyridine Parkinson disease mouse model via producing glucagon-like peptide-1. J Neurochem 150: 441-452, 2019.

33. Zheng C, Chen T, Wang Y, Gao Y, Kong Y, Liu Z and Deng X: A randomised trial of probiotics to reduce severity of physiological and microbial disorders induced by partial gastrectomy for patients with gastric cancer. J Cancer 10: 568-576, 2019.

34. Bolger AM, Lohse M and Usadel B: Trimmomatic: A flexible trimmer for Illumina sequence data. Bioinformatics 30: 2114-2120, 2014.

35. Edgar RC: UPARSE: Highly accurate OTU sequences from microbial amplicon reads. Nat Methods 10: 996-998, 2013.

36. Arung W, Meurisse M and Detry O: Pathophysiology and prevention of postoperative peritoneal adhesions. World J Gastroenterol 17: 4545-4553, 2011. 
37. Gemmati D, Occhionorelli S, Tisato V, Vigliano M, Longo G Gonelli A, Sibilla MG, Serino ML and Zamboni P: Inherited genetic predispositions in F13A1 and F13B genes predict abdominal adhesion formation: Identification of gender prognostic indicators. Sci Rep 8: 16916, 2018.

38. Li S, Chen T, Xu F, Dong S, Xu H, Xiong Y and Wei H: The beneficial effect of exopolysaccharides from bifidobacterium bifidum WBIN03 on microbial diversity in mouse intestine. J Sci Food Agric 94: 256-264, 2014

39. Mary Ellen S, Francisco G, Richard G, Holt PR, Quigley EM, Sartor RB, Sherman PM and Mayer EA: An update on the use and investigation of probiotics in health and disease. Gut 62: 787-796, 2013.

40. Floch MH: The role of prebiotics and probiotics in gastrointestinal disease. Gastroenterol Clin North Am 47: 179-191, 2018.

41. Zhu D, Chen X, Wu J, Ju Y, Feng J, Lu G, Ouyang M, Ren B and Li Y: Effect of perioperative intestinal probiotics on intestinal flora and immune function in patients with colorectal cancer. Nan Fang Yi Ke Da Xue Xue Bao 32: 1190-1193, 2012 (In Chinese).

42. Li JH, Zhu HJ, Huang XR, Lai KN, Johnson RJ and Lan HY: Smad7 inhibits fibrotic effect of TGF-Beta on renal tubular epithelial cells by blocking Smad2 activation. J Am Soc Nephrol 13: 1464-1472, 2002.

43. Pan R, Zhang Y, Zang B, Tan L and Jin M: Hydroxysafflor yellow A inhibits TGF- $\beta 1$-induced activation of human fetal lung fibroblasts in vitro. J Pharm Pharmacol 68: 1320-1330, 2016.

44. Bi J, Zhang S, Du Z, Zhang J, Deng Y, Liu C and Zhang J: Peripheral serotonin regulates postoperative intra-abdominal adhesion formation in mice. Sci Rep 7: 10001, 2017.

45. Elmadhun NY, Sabe AA, Lassaletta AD, Dalal RS and Sellke FW: Effects of alcohol on postoperative adhesion formation in ischemic myocardium and pericardium. Ann Thorac Surg 104: 545-552, 2017.
46. Guo H, Leung JC, Cheung JS, Chan LY, Wu EX and Lai KN: Non-Viral Smad7 gene delivery and attenuation of postoperative peritoneal adhesion in an experimental model. Br J Surg 96: 1323-1335, 2009

47. Wei G, Wu Y, Gao Q, Shen C, Chen Z, Wang K, Yu J, Li X and Sun X: Gallic acid attenuates postoperative intra-abdominal adhesion by inhibiting inflammatory reaction in a rat model. Med Sci Monit 24: 827-838, 2018

48. Xu J, Lu C, Liu Z, Zhang P, Guo H and Wang T: Schizandrin B protects LPS-induced sepsis via TLR4/NF- $\kappa \mathrm{B} / \mathrm{MyD} 88$ signaling pathway. Am J Transl Res 1155-1163, 2018.

49. Wu W, Wang F, Gao X, Niu T, Zhu X, Yan X and Chen H: Synergistic effect of kappa-carrageenan on oxazolone-induced inflammation in BALB/c mice. BMC Gastroenterol 16: 41, 2016.

50. Kant R, Rasinkangas P, Satokari R, Pietila TE and Palva A: Genome sequence of the butyrate-producing anaerobic bacterium anaerostipes hadrus PEL 85. Genome Announc 3: e00224-e00215, 2015.

51. Wopereis H, Sim K, Shaw A, Warner JO, Knol J and Kroll JS: Intestinal microbiota in infants at high risk for allergy: Effects of prebiotics and role in eczema development. J Allergy Clin Immunol 141: 1334-1342, 2018.

52. Kiseleva MN, Nikulenkova TS and Kuznetsova LS: Etiologic role of klebsiella in children with acute intestinal diseases. Zh Mikrobiol Epidemiol Immunobiol 50-52, 1976 (In Russian).

53. Ochieng JB, Boisen N, Lindsay B, Santiago A, Ouma C, Ombok M, Fields B, Stine OC and Nataro JP: Serratia marcescens is injurious to intestinal epithelial cells. Gut Microbes 5: 729-736, 2014.

54. Hager CL and Ghannoum MA: The mycobiome: Role in health and disease, and as a potential probiotic target in gastrointestinal disease. Dig Liver Dis 49: 1171-1176, 2017. 